\title{
Micropore Characteristics and Geological Significance of Shale Reservoirs: Case Study of Fuling Shale Gas in Sichuan Basin, China
}

\author{
Liang Cheng, ${ }^{1,2,3}$ Fujia Guan $\mathbb{D}^{1,2,3}$ Dehua Liu, ${ }^{1,2,3}$ Wenxin Yang, ${ }^{4}$ and Jing Sun ${ }^{1,2,3}$ \\ ${ }^{1}$ School of Petroleum Engineering, Yangtze University, Caidian, 430100 Wuhan, China \\ ${ }^{2}$ Hubei Drilling and Recovery Engineering for Oil and Gas Key Lab, Yangtze University, Caidian, 430100 Wuhan, China \\ ${ }^{3}$ Hubei Province Engineering Research Center for Shale Gas Development, Yangtze University, Caidian, 430100 Wuhan, China \\ ${ }^{4}$ Jianghan Oilfield Company, Guanggu, 430100 Wuhan, China
}

Correspondence should be addressed to Fujia Guan; 500636@yangtzeu.edu.cn

Received 10 November 2020; Revised 17 March 2021; Accepted 9 April 2021; Published 27 May 2021

Academic Editor: Shiyuan Zhan

Copyright (c) 2021 Liang Cheng et al. This is an open access article distributed under the Creative Commons Attribution License, which permits unrestricted use, distribution, and reproduction in any medium, provided the original work is properly cited.

\begin{abstract}
Several techniques (such as scanning electron microscopy (SEM) and gas adsorption systems) have been used to study the pore features and structures of shale reservoirs. The available methods and techniques have restricted the specific research on micropores, and the morphology, genesis, volume, and main factors controlling pore characteristics are yet to be analyzed. Currently, there is no systematic understanding of the role that these spaces play in gas storage and flow. As such, our understanding of the spatial connectivity of pores and reserves of shale reservoirs is limited. In this study, the pores of the Fuling shale gas reservoir in the Sichuan Basin were systematically observed by SEM and transmission electron microscopy. Images of pores smaller than $2 \mathrm{~nm}$ were captured for the first time, and their morphology and genesis were analyzed by combining these images with the rock mineralogy theory. The pore size distribution characteristics of the reservoir were analyzed by the adsorption-mercury injection method and nuclear magnetic resonance, and the main factors controlling the distribution of different pore sizes were analyzed. The results show that large numbers of micropores were distributed between the mesopores and macropores in the shale reservoir, which mainly consisted intergranular pores, intermolecular pores, interlamellar pores of clay minerals, and organic matter skeleton pores. The development of pores smaller than $1 \mathrm{~nm}$ was mainly controlled by the clay mineral content, and the development of pores with a size of approximately 1-2 nm was related to the contents of clay minerals and organic matter. These pores could connect the macropores and mesopores well, which is important for gas storage and flow. In this paper, the types, distribution, and main controlling factors of micropores were studied, and our understanding of the reservoir space was improved from the nanometer level to the Angstrom level, which is important for gas storage and flow process analysis.
\end{abstract}

\section{Introduction}

As a typical unconventional oil and gas resource, shale gas is widely valued worldwide. Shale differs from conventional oil and gas reservoirs, with a small pore-throat radius and complex pore structure [1]. It is difficult to accurately characterize shale reservoir pore systems by traditional technical methods, such as high-pressure mercury injection, and the pore size and structure are important factors affecting the shale gas reserves and production of reservoirs. As such, the characterization of shale reservoir pore systems has attracted the attention of scholars. Several advancements have been made in the characterization and classification of the pore structures of shale reservoirs by using materials science research methods such as scanning electron microscopy (SEM) and gas adsorption. However, our understanding of the properties of small pores is lacking. In this study, several advanced methods were used to study the micropores 
$(<2 \mathrm{~nm})$ of the Fuling shale reservoir in the Sichuan Basin, China, to enhance our understanding of the properties and functions of these pores.

Since Singh et al. first proposed the concept of "nanoscale pores" in microscopic shale reservoirs [2], many scholars have proposed classification schemes based on the two aspects of pore size scale and genetic type: the IUPAC and Chalmers and Bustin divided the pores of shale reservoirs into macropores $(>50 \mathrm{~nm})$, mesopores $(2-50 \mathrm{~nm})$, and micropores $(<2 \mathrm{~nm})[3,4]$, while Passey, Sondergeld, Slatt, Chen, and Yu proposed classification schemes based on the pores' origins. Currently recognized pore types include organic matter pores, intergranular pore dissolution pores, microfractures, and others [5-10]. Some studies have reported that there is an inverse relationship between pore size and specific surface area [11], and micropores contribute a larger proportion of the specific surface area, followed by mesopores, with macropores contributing the smallest proportion. However, Chalmers and Bustin and Ross and Bustin reported that the specific surface area increased with an increase in the micropore volume [12-14]. The specific surface area directly affects the amount of methane adsorption in the reservoir. Javadpour proposed that in addition to their presence in nanoscale pores as free and adsorbed gas, gas molecules are also dispersed in materials, such as kerogen, as dissolved gas [15]. The spaces in which dissolved gas can be deposited might be smaller than nanoscale pores and have garnered considerable interest; however, our understanding of these spaces is lacking.

The demand for intuitive observations of pore size and morphology is high among geologists [16]. SEM, nanometer computed tomography (CT), and other technologies are used to observe shale pores. Owing to the limitations of the fieldof-view size and resolution, only pores larger than tens of nanometers can be observed in a local area. Researchers have begun to test technologies with higher resolution to observe smaller pores. Javadpour observed nanopores and nanoscale grooves in shale reservoirs using atomic force microscopy [17]. However, most images have captured mesopores, and no images of smaller micropores have been obtained. Gareth and Chalmers used focused ion beam (FIB) milling and transmission electron microscopy (TEM) to study the reservoir spaces in the reservoir [18]. Owing to the limitations of their equipment, images of pore features smaller than $2 \mathrm{~nm}$ could not be obtained. However, this combination of technologies provided a good reference for future work.

Physical imaging cannot fully describe the pore structure characteristics of reservoirs. Therefore, physical adsorption, mercury injection, nuclear magnetic resonance (NMR), and other technologies are required to study the pore size distribution (PSD) characteristics [19]. High-pressure mercury injection and gas adsorption are widely used analytical methods; however, high-pressure mercury injection can only detect the distributions of large pores, and the aperture detection range of the gas adsorption method is closely related to the molecular size of the injected gas; thus, it is difficult to determine the distribution characteristics of all pores using one method. Clarkson et al. and Gareth and Chalmers combined the low-temperature carbon dioxide, nitrogen, and high-pressure mercury methods to obtain the PSD characteristics of shale reservoirs $[18,20]$. Recently, NMR has been widely used in oil and gas exploration fields, such as the logging and characterization of the pore structure. The main advantage of this approach is that the porosity and PSD of rock strata can be obtained accurately without the influence of the structural composition. The PSD can be measured by NMR based on the NMR T2 spectrum of saturated singlephase fluid, which can reflect the internal pore structure, and is converted by the positive correlation between the pore size and relaxation time T2 of the fluid. When the pore is a single-phase fluid, the pore size can be directly calibrated, and the proportions of pores with different scales can be characterized.

In this study, field emission TEM was used to observe the shale reservoirs of the upper Ordovician Wufeng Formation and Lower Silurian Longmaxi Formation in the Fuling area of the Sichuan Basin due to its high resolution of up to $0.14 \mathrm{~nm}$. The super-microscopic pore spaces of the brittle minerals, clay mineral particles, and organic matter skeletons were observed, and the proportions of these spaces and their main controlling factors were analyzed by gas adsorption, mercury injection, NMR, and other technologies. The roles of these spaces in gas molecular storage and flow were then analyzed, which is important for attaining an in-depth understanding of the spatial characteristics of micropores in shale reservoirs and their gas flow processes.

\section{Methodology}

2.1. Sample Source. The samples used in this study were all obtained from the upper Ordovician Wufeng Formation and Lower Silurian Longmaxi Formation in the Fuling shale gas field, Sichuan Basin, China, which is a set of deep-sea shelf facies shale deposits. The formation can exceed $100 \mathrm{~m}$ in thickness, with nine sublayers. The lower one to five layers have higher organic carbon and lower clay mineral contents than the upper six to nine layers and act as the main production layers [21]. Figure 1 shows the geographical location, stratigraphic division, and sampling location of the Fuling shale gas field.

Columnar samples were obtained from well 1, distributed in five sublayers. To better study the micropore characteristics of the reservoir, the total porosity, mineral composition, organic carbon content, and pore structure characteristics were determined, and SEM and TEM analyses were conducted for each sample.

2.2. Mineral and Organic Matter Contents. The rock samples were crushed to 200-300 mesh, dried, mixed with ethanol, ground by hand using a mortar and pestle, and then smeared on a glass slide for X-ray diffraction analysis to measure the sample's mineral content. A Japanese neo-Confucianism SmartLab diffractometer was used for the X-ray diffraction analysis.

The total organic carbon content was determined following the sulfur-carbon method. After crushing the sample, the inorganic carbon in the sample was removed by dilute hydrochloric acid and then burned in the oxygen stream at 900- 

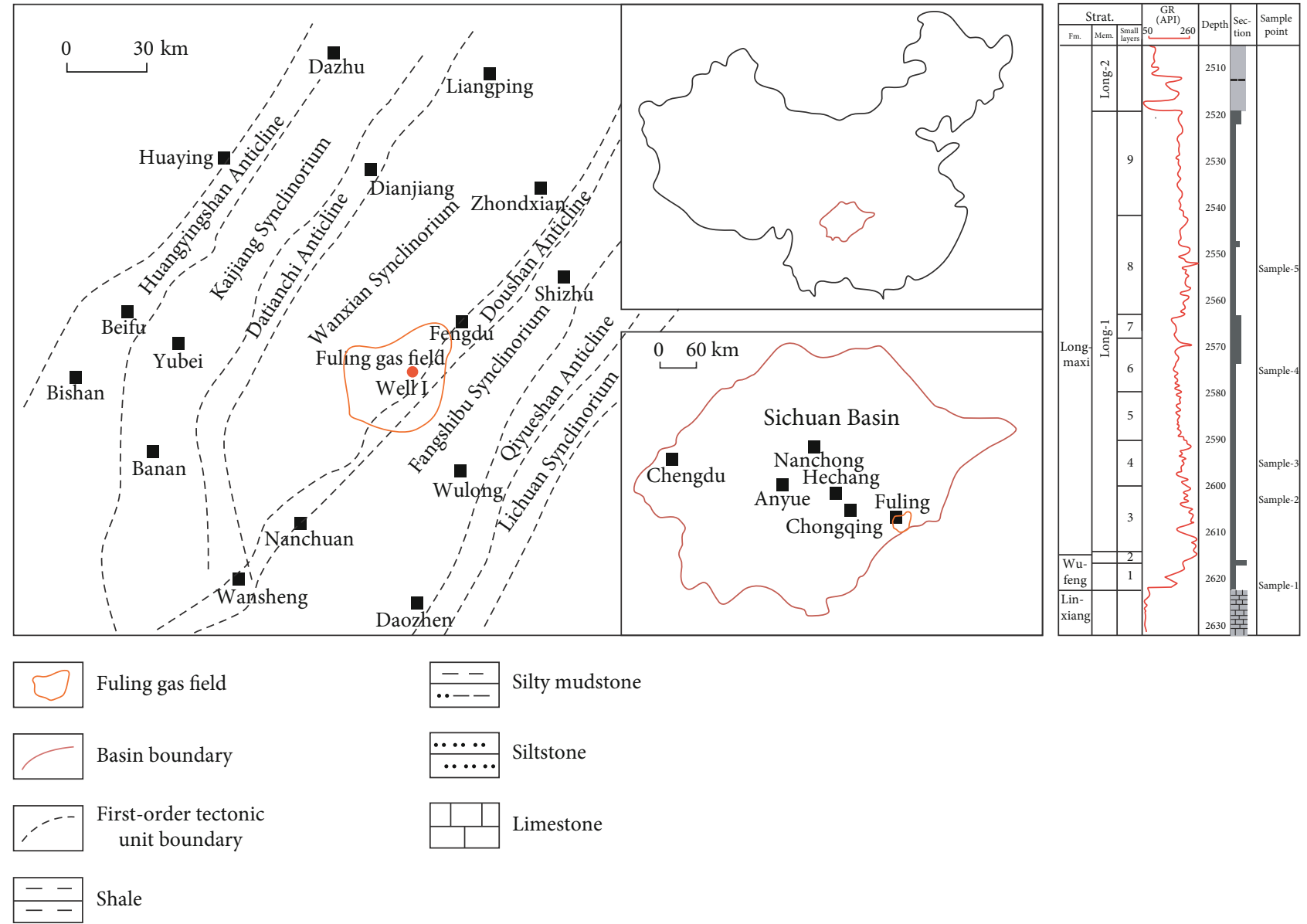

FIGURE 1: Geographical location of the Fuling shale gas field.

TABLE 1: Basic sample information.

\begin{tabular}{lccccc}
\hline Sample & $\begin{array}{c}\text { Depth } \\
(\mathrm{m})\end{array}$ & Sublayer & $\begin{array}{c}\text { Porosity } \\
(\%)\end{array}$ & $\begin{array}{c}\text { TOC } \\
(\%)\end{array}$ & $\begin{array}{c}\text { Clay mineral } \\
\text { content }(\%)\end{array}$ \\
\hline 1 & 2621.3 & 1 & 5.5 & 6.3 & 19.1 \\
2 & 2603.4 & 3 & 5.2 & 5.4 & 26.1 \\
3 & 2595.6 & 4 & 5.1 & 4.1 & 29.6 \\
4 & 2575.1 & 6 & 3.6 & 1.8 & 38.4 \\
5 & 2553.1 & 8 & 3.4 & 1.3 & 58.8 \\
\hline
\end{tabular}

$1000^{\circ} \mathrm{C}$ to convert the total organic carbon into carbon dioxide. The total organic carbon content was calculated using infrared detector detection data.

2.3. Physical Characteristics. The porosity of the samples was measured following the Boyer two-chamber method. The injection fluid was helium gas, and the rock samples were columnar, with a diameter and height of 2.5 and $10 \mathrm{~cm}$, respectively. The apparent volume was measured following the kerosene method, and the final porosity was taken as the ratio of the injected gas volume to the apparent volume of the rock sample.

2.4. Observation by SEM and TEM. Field emission SEM and TEM have different advantages. Currently, SEM can distin- guish mineral types well; however, the resolution is insufficient for observing micropores. Field emission highresolution TEM can be used to observe micropores but requires sample thickness less than $100 \mathrm{~nm}$, and it cannot easily distinguish mineral species. The combination of these technologies can facilitate the analysis of the micropore characteristics and occurrence and their causes.

First, the samples were cut into sections of approximately $1 \mathrm{~mm}$ in thickness. One surface of the samples was mechanically ground flat, and the surface of the thin shale sections was then bombarded with argon ions using an ion-thinning device. The polished samples were fixed to the sample stage with a conducting adhesive and coated with a gold layer to increase the conductivity of the shale's surface, thereby improving the SEM observation.

The prepared samples were placed in the sample chamber of a FEI Helios Model 650 Focused Ion Beam-Scanning Electron Microscope (FIB-SEM). After vacuuming the sample chamber, the electron beam was switched on, and the desired area was selected, with a size of $6 \times 3 \mu \mathrm{m}$. The samples were then cut using a $30 \mathrm{kV}$ gallium ion beam to reduce the sample thickness to $100 \mathrm{~nm}$ or less and mounted to a copper grid. Finally, the prepared samples were analyzed under a Tecnai G2 F30 (FEI, Holland) field emission TEM with dot and line resolutions of 0.14 and $0.2 \mathrm{~nm}$, respectively. This combination allows the observation of fine mesopores and 


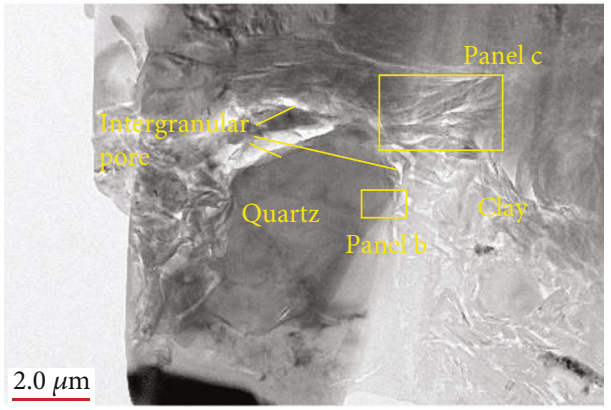

(a)

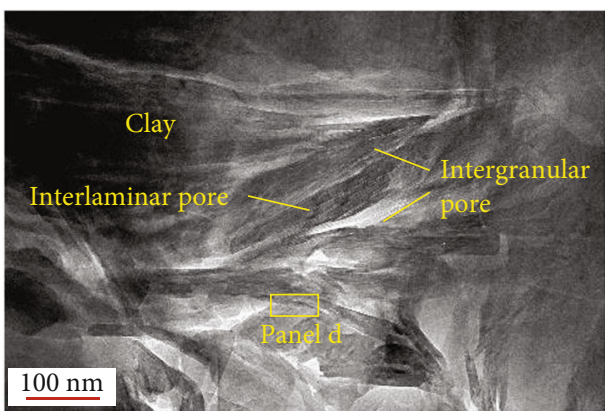

(c)

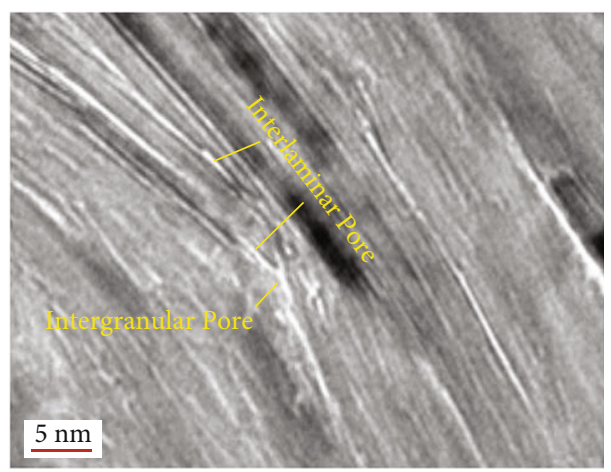

(e)

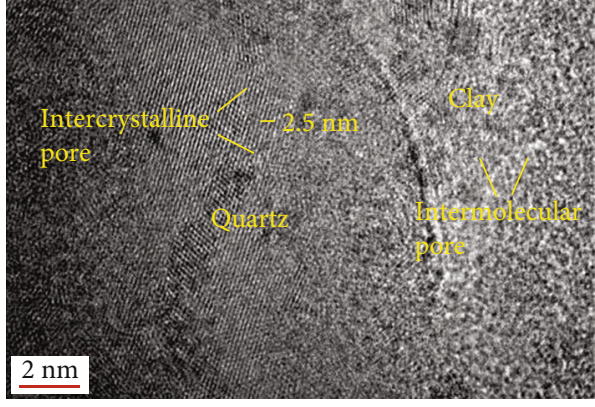

(b)

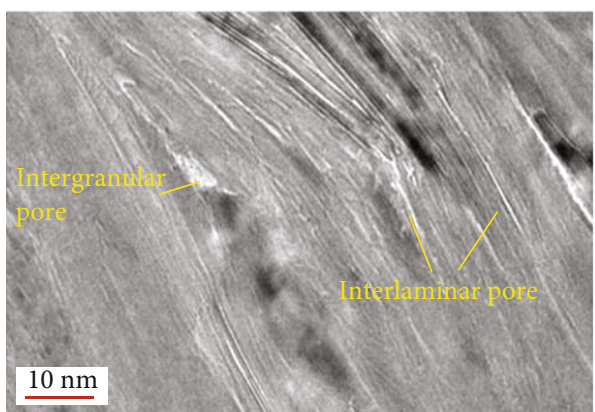

(d)

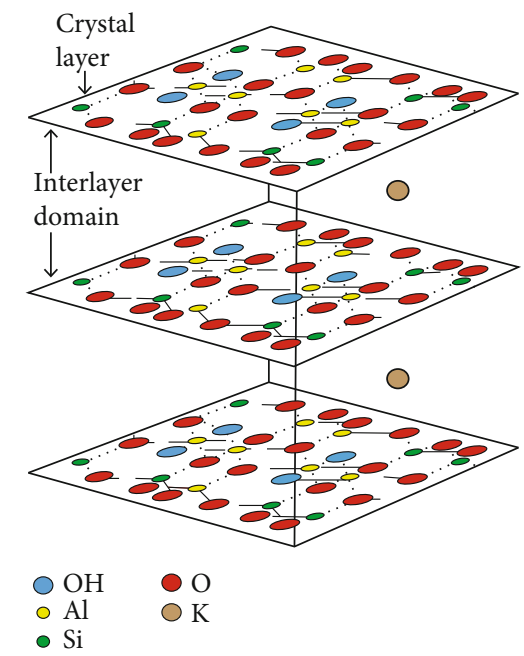

(f)

FIGURE 2: Microscopic pore characteristics. (a) Distribution characteristics of the intergranular pores. (b) Characteristics of the lattice quartz particles and intermolecular pores of the clay minerals. (c) Characteristics of intergranular pores, interlaminar pores. (d) Deformational characteristics of the clay mineral lamellar crystals and interlaminar pores. (e) Two ends of the interlaminar pores (slits) were connected to the interparticle pores. (f) Diagram of the layered structure of illite. Note: white areas shown in the TEM images are the pores.

micropores within shale reservoirs and causing little damage to the original structure.

Owing to the limited field-of-view, the sample must be fully observed under SEM before selecting the representative areas and cutting segments for TEM observation to ensure that the observations of the reservoir are more comprehensive. These areas include brittle minerals (such as dolomite and quartz), clay minerals (such as illite), organic matter, areas with a large pore distribution, and areas with no pores.

2.5. Pore Structure. The pore structure of shale reservoirs is complex, and their pore sizes span several orders of magni- tude. In this study, the pore structure of a shale reservoir was analyzed by high-pressure mercury-low-temperature gas adsorption and NMR, and the results were compared and analyzed.

2.5.1. High-Pressure Mercury Injection and Low-Temperature Gas Adsorption Analysis. High-pressure mercury injection and low-temperature gas adsorption were used in conjunction, as follows: low-temperature $\left(0^{\circ} \mathrm{C}\right) \mathrm{CO}_{2}$ adsorption for apertures smaller than $2 \mathrm{~nm}$ was used for the detailed analysis of the pore distributions, and cryogenic nitrogen gas adsorption was used to analyze the aperture porosity distribution 


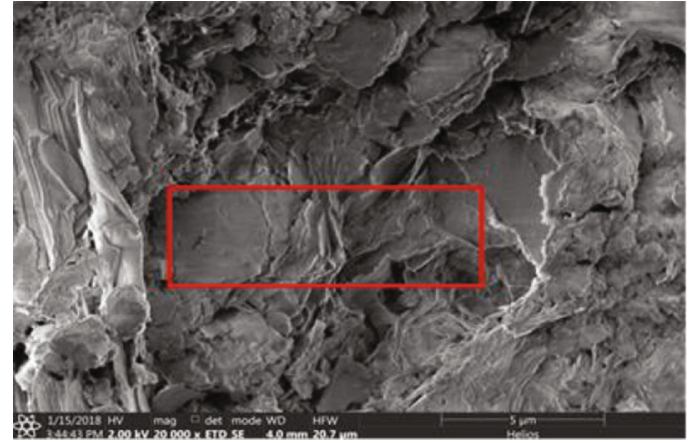

(a)

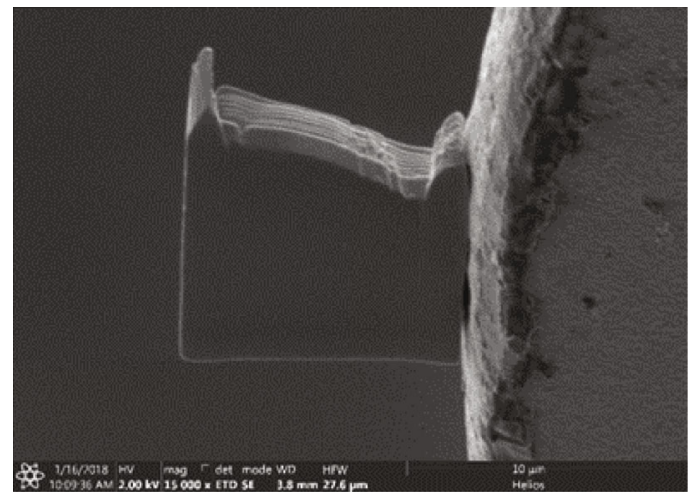

(c)

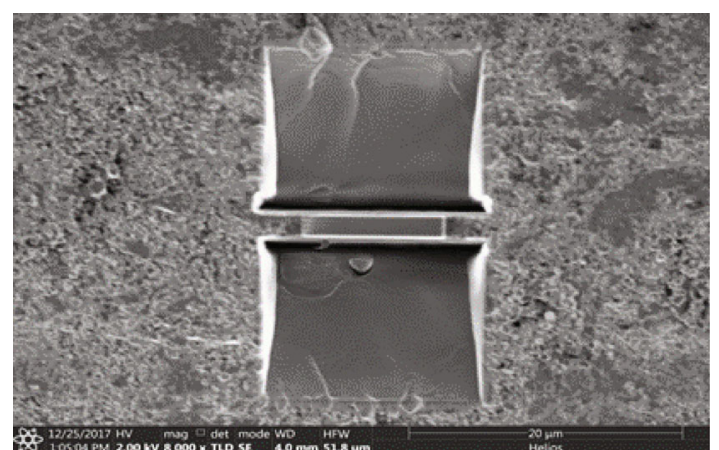

(b)

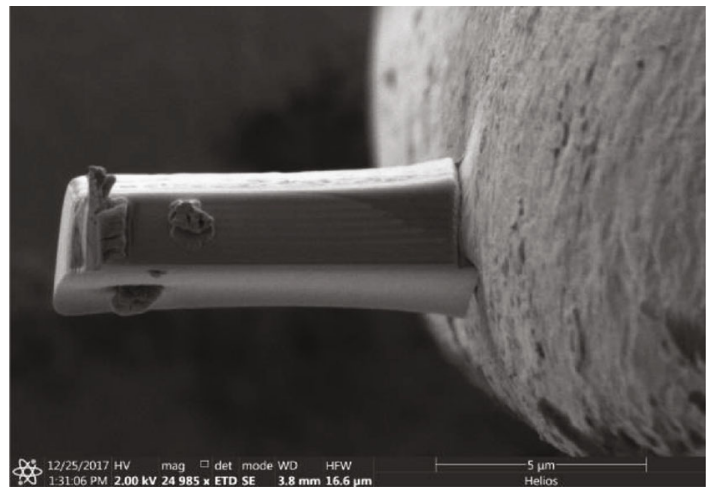

(d)

Figure 3: Sample preparation process. (a) Selection of a suitable area under SEM. (b) Cutting the selected area. (c) Thinning the sample. (d) Fixing the sample.

between 2 and $50 \mathrm{~nm}$ with high resolution. High-pressure mercury injection can represent the distribution of pores larger than $50 \mathrm{~nm}$. The data obtained by the three analysis methods were spliced, and the aperture distribution curve for pores of each size in the reservoir was then obtained. An Autosorb-IQ2 specific surface and aperture distribution analyzer from Kantar Instruments were used in the lowtemperature gas adsorption experiment. The sample was first crushed to $60-80$ mesh and then vacuumed at $110^{\circ} \mathrm{C}$ to remove any water and volatile substances from the pores of the sample. The degassing was conducted for $12 \mathrm{~h}$, and then the adsorption experiment was conducted.

2.5.2. NMR Analysis. Cylindrical samples ( 2.5 and $3-5 \mathrm{~cm}$ in diameter and length, respectively) were selected and then vacuumed in a $110^{\circ} \mathrm{C}$ environment, regardless of the moisture and volatile matter contents of the sample pores, with a degassing time of over $12 \mathrm{~h}$. After degassing, the samples were completely saturated with water. According to the T2 spectrum in the NMR method, the T2 rock pore fluid can indicate the pore diameter, with long T2 corresponding to large pores and short T2 corresponding to small pores. As both the core NMR T2 spectrum and mercury injection analysis data reflect the pore structure characteristics of the rock, the two sets of data were well correlated. Therefore, when the T2 spectrum could be converted into the pore radius distribution, reflecting the pore structure characteristics of the rock, the data were corrected with the mercury injection data to improve their accuracy.

\section{Results}

3.1. Basic Sample Information. As shown in Table 1, the five selected samples were distributed among five sublayers, and the porosity gradually decreased from bottom to top. The porosity of the lower five layers generally exceeded $5 \%$, while that of the upper four layers was generally below $4 \%$. The organic carbon content gradually decreased from bottom to top, and the clay mineral content gradually increased.

\subsection{Micropore Characteristics under TEM}

3.2.1. Inorganic Microporous. The inorganic pores visible under SEM mainly included intergranular, brittle mineral intercrystalline, and dissolution pores. The inorganic pores in the shale reservoir of the upper Ordovician Wufeng Formation and Lower Silurian Longmaxi Formation in the Fuling area were mainly composed of intergranular pores between clay and brittle minerals (Figure 2(a)).

Thin sections of quartz and clay mineral development were selected and observed under field emission TEM. At a small magnification ratio, quartz was distributed among the clay minerals in an isolated manner. There were intergranular pores between the quartz and clay minerals with diameters reaching dozens of nanometers (Figure 2(a)), which were consistent with the SEM results (Figure 3(a)). Clay mineral particles were arranged between a large number of intergranular pores. Most of the pores in the long axis-direction parallel to the grain direction of the basic aperture were 


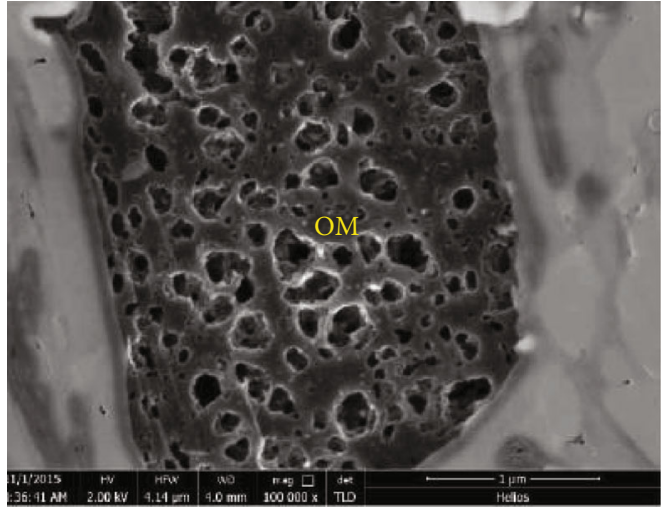

(a)

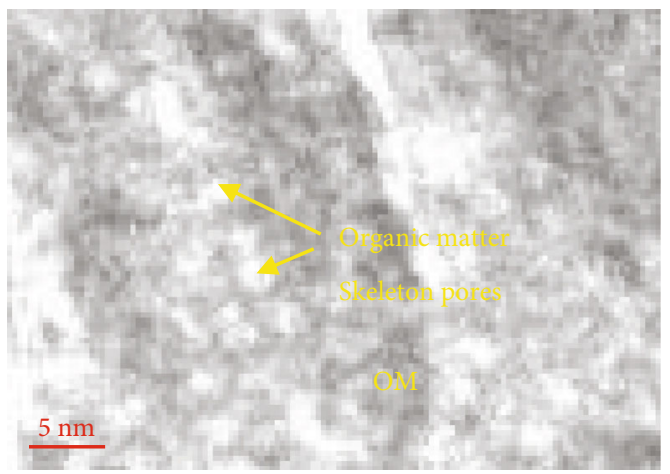

(c)

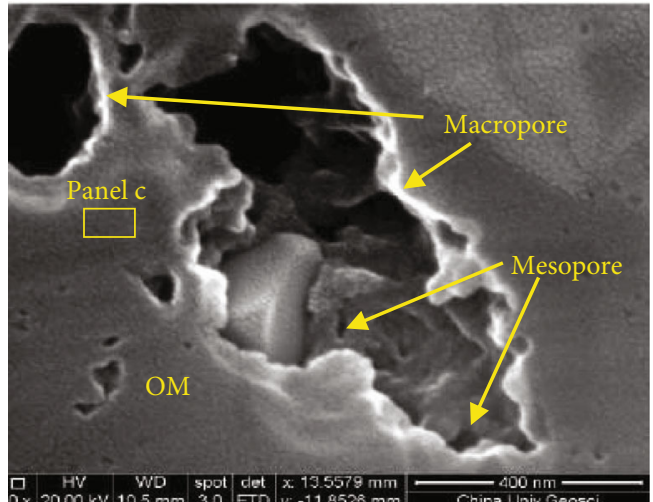

(b)

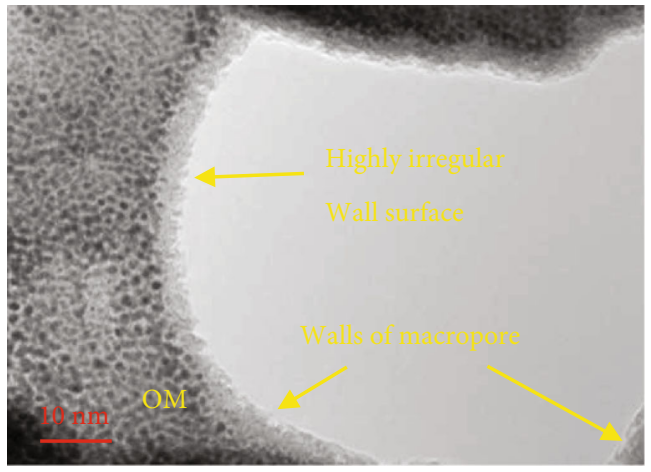

(d)

FIgure 4: Characteristics of the organic pores. (a) Planar distribution characteristics of the organic pores (SEM). (b) Organic pore characteristics (SEM). (c) Characteristics of the organic matter skeleton pores (TEM). (d) Micropores in the organic pore wall (TEM).

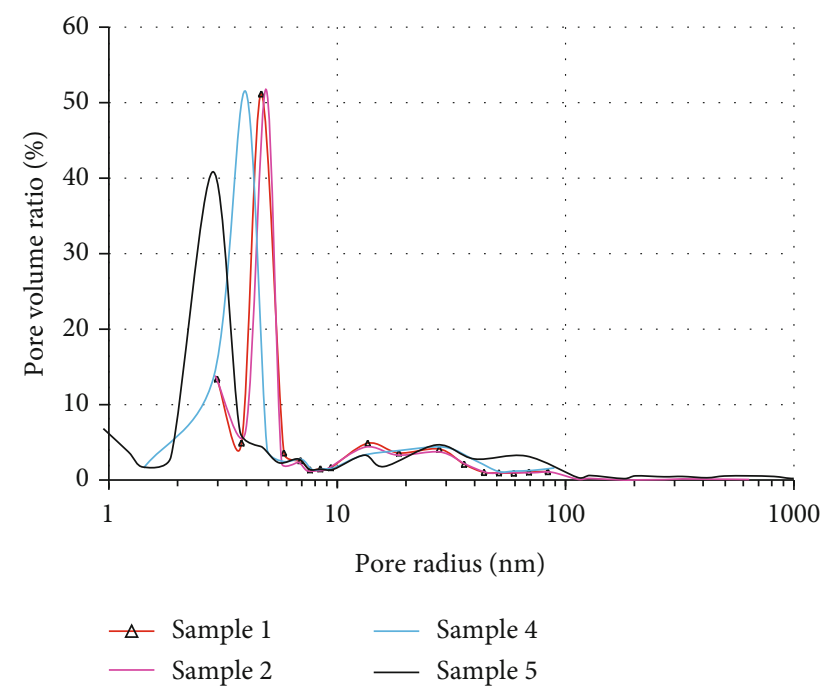

FIGURE 5: Pore size distribution characteristics of the adsorptionmercury injection method.

mainly mesopores that were several to dozens of nanometers in size, which connected with one other through the porethroats (Figure 2(a)). The TEM images presented smaller clay mineral particles than those observed in the SEM images and significantly more particles and pores (Figure 2(a)). This shows that the clay minerals observed in the SEM were aggregate of clay mineral particles, which also contained smaller intergranular pores. As the scale gradually increased, a large number of crystal gaps were observed in the grains of brittle and clay minerals, and there was a clear gap between the quartz crystals with an approximate aperture of $0.25 \mathrm{~nm}$ (Figure 2(b)).

The clay mineral crystals exhibited a very well-developed layered structure, which was formed by combining several thin crystal structures to form a crystal layer. There was no notable lattice distribution on the surface of the crystal layer. However, a large number of very small pores $(0.1-1 \mathrm{~nm})$ were randomly distributed across the surface, which consisted of the solid intermolecular interspaces of the crystal layer, which could be referred to as the intermolecular pores (Figure 2(b)). There was a certain distance between the crystal layers, and the width of the interlaminar pores (slits) formed between the layers was approximately $1 \mathrm{~nm}$ (Figure 2(c)). When the lamellar clay mineral particles were subjected to extrusion deformation, a microfold formed between the inner lamellar crystals, and an approximate slippage formed in the deformed core region, thereby increasing the size of the interlaminar pores (Figure 2(d)). These interlaminar pores (slits) were parallel to the flaky crystals, and the two ends were typically connected to the interparticle macropore or mesopores (Figure 2(e)), which plays an important role in improving the connectivity of interparticle pores. 


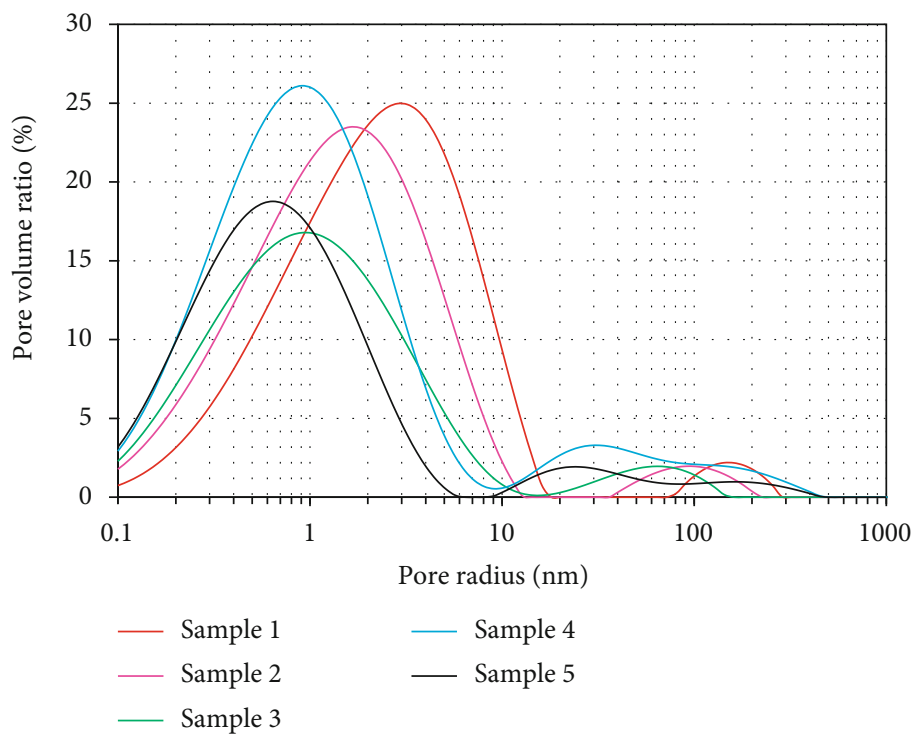

FIgURE 6: Pore size distribution characteristics obtained by NMR.

TABle 2: Peak aperture and micropore volume ratio measured by different methods.

\begin{tabular}{|c|c|c|c|c|}
\hline \multirow[b]{2}{*}{ Sample } & \multicolumn{2}{|c|}{$\begin{array}{l}\text { Adsorption-mercury } \\
\text { injection method }\end{array}$} & \multicolumn{2}{|c|}{$\begin{array}{l}\text { Nuclear magnetic } \\
\text { resonance method }\end{array}$} \\
\hline & $\begin{array}{l}\text { Peak pore } \\
\text { diameter } \\
(\mathrm{nm})\end{array}$ & $\begin{array}{c}\text { Micropore } \\
\text { volume ratio } \\
(\%)\end{array}$ & $\begin{array}{c}\text { Peak pore } \\
\text { diameter } \\
(\mathrm{nm})\end{array}$ & $\begin{array}{c}\text { Micropore } \\
\text { volume ratio } \\
(\%)\end{array}$ \\
\hline 1 & 4.9 & 12.62 & 5.6 & 18.89 \\
\hline 2 & 4.7 & 12.93 & 3.2 & 25.39 \\
\hline 3 & 3.1 & 13.31 & 2.4 & 29.97 \\
\hline 4 & 3.7 & 14.12 & 1.5 & 32.38 \\
\hline 5 & 2.7 & 14.23 & 1.1 & 37.34 \\
\hline
\end{tabular}

Figure 2(f) shows a layered structure diagram of illite. Previous studies suggested that layered structures exist in clay minerals, such as montmorillonite, illite, and kaolinite. The interlaminar spacing varied from 0.7 to $4 \mathrm{~nm}$, and the interlaminar forces were weak. The interlaminar spacing of kaolinite, illite, and montmorillonite, which are major clay minerals, is $0.72,1$, and $0.96-4 \mathrm{~nm}$, respectively.

3.2.2. Organic Pores. Organic pores are generated by the shrinkage of the kerogen volume during hydrocarbon generation. The SEM results indicated that some irregular shapes and disconnected pores existed on the kerogen's surface (Figure 4(a)). The pore size and surface porosity are significantly related to the degree of kerogen thermal evolution; the pores were mostly mesopores and macropores. Some mesopores were present within the macropores (Figure 4(b)) and were observed to be interconnected. Smaller organic pores were mostly isolated and had poor connectivity with the other pores (Figure 4(b)). The solids between these macropores and mesopores are called organic matter skeleton, in which there are a lot of micropores with an aperture of approximately $2 \mathrm{~nm}$ was visible under TEM and varied in size and shape (Figure 4(c)). These pores may be solid intermolecular pores in the organic matter, or they may have extremely small shrinkage pores, making it difficult to fully understand the pore properties based on the current image observations, so these micropores were collectively referred to as the organic matter skeleton pores. They make the macropores or mesopores around the organic matter skeleton that can be well connected. Gareth and Chalmers observed the irregular surface of pore walls by TEM [18] and found numerous micropores that were approximately $2.5 \mathrm{~nm}$ in diameter. They are also organic matter skeleton pores (Figure $4(\mathrm{~d})$ ). These pores increased the surface area of the macropores and created irregular surfaces in the macropore walls. The opening of some pores to the macropores is indicating that there was good connectivity between the organic matter skeleton pores, mesopores, and macropores.

3.3. Pore Structure. The distribution of the sizes of pores in the shale reservoir was wide, with both nanometer and micron-sized pores. Figures 5 and 6 show the pore structure distribution characteristics of the five samples tested by adsorption-mercury injection and NMR, respectively. The shapes of the PSD curves obtained by the two methods were similar. The reservoir was mainly composed of micropores and mesopores, accounting for over $80 \%$ of the total pore spaces, while the macropores were relatively undeveloped. The peak PSD was between 0 and $10 \mathrm{~nm}$, indicating that the number and proportion of micropores were relatively large, which significantly influenced the reservoir properties. The mercury-adsorption injection results showed that the PSD exhibited multiple peaks, while the pore diameter distribution curve measured by NMR was bimodal. Table 2 presents the detailed statistical analysis data. The peak aperture and proportion of micropores of the same sample measured 


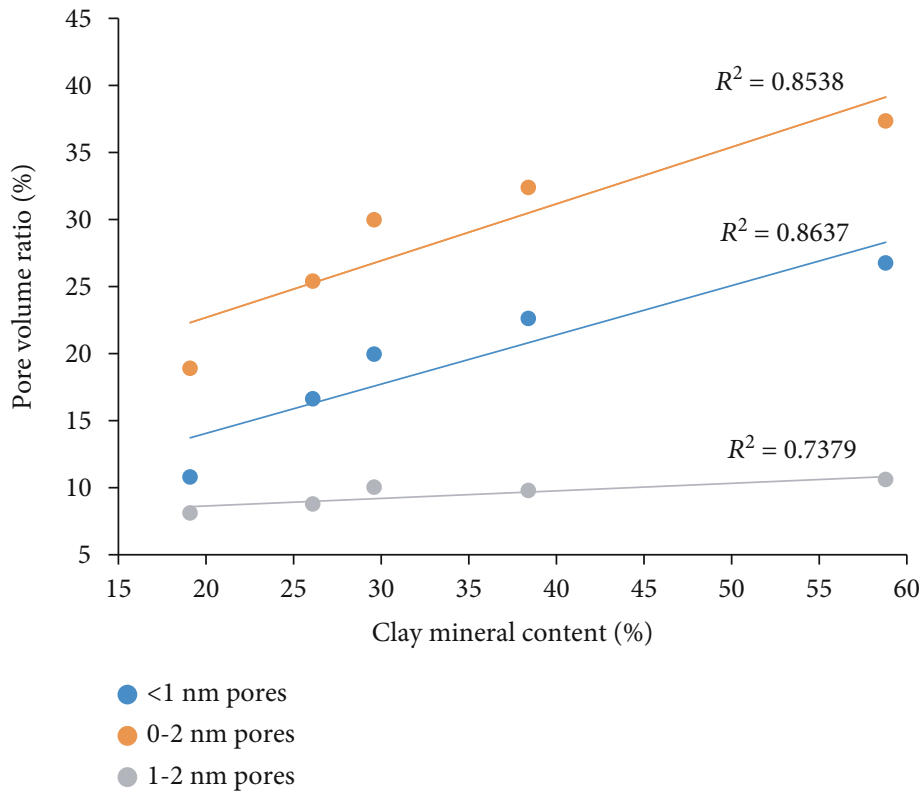

Figure 7: Relationship between the clay mineral content and pore volume ratio.

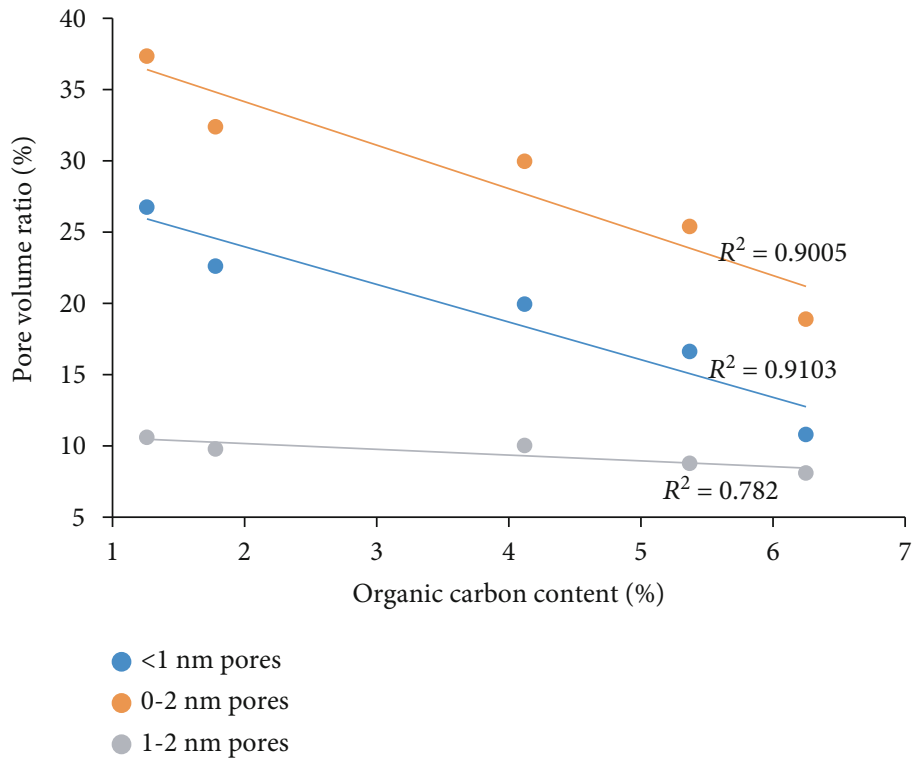

FIgURE 8: Relationship between the organic carbon content and pore volume ratio.

TABLE 3: Classification of micropore types.

\begin{tabular}{lccc}
\hline Cause & Pore type & Aperture $(\mathrm{nm})$ & Distribution characteristics \\
\hline & Intercrystalline pore of brittle mineral & $0.2-0.3$ & Between brittle mineral crystals \\
Inorganic pore & Intergranular pores of clay minerals & $1-2$ & Between small particles in the aggregate of clay minerals \\
& Interlaminar pores of clay minerals & $0.8-2$ & Between the crystalline layers of clay minerals \\
Organic pore & Intermolecular pores of clay minerals & $0.3-0.6$ & Between the molecules of clay minerals \\
\hline
\end{tabular}


by the two methods slightly differed; however, the change trend was relatively consistent.

Generally, adsorption-mercury injection and NMR could better characterize the shale pore size and PSD. The test pore size data were similar, and the PSD was consistent. However, the resolution of the mesopore and micropore PSD of the adsorption and mercury injection data was higher, while the resolution of NMR was better for determining the PSD of micropores. For the adsorption-mercury injection method, the sample must be crushed, which increases the specific surface area and changes the original pore structure to a certain extent, while the core remains intact for the NMR method; as such, the NMR method was more suitable for analyzing smaller pores.

\section{Discussion}

4.1. Main Factors Controlling Micropore Development. According to the test data obtained by NMR, the proportion of micropores was closely related to the organic matter and clay mineral contents. The higher the organic matter content, the smaller the micropore volume, and the higher the clay mineral content, the larger the micropore volume ratio. According to the peak pore diameter of each sample, as the burial depth increased, the organic matter content increased, and the peak pore diameter also increased. The peak PSD of the upper sublayer samples $(4,5)$, with a high clay mineral content, was approximately $1 \mathrm{~nm}$. However, the organic matter content of the lower sublayers (samples 1,2, and 3) was higher, and the peak pore diameter peak exceeded $2 \mathrm{~nm}$. Figures 7 and 8 show the volume ratios of pores less than $1 \mathrm{~nm}$ and indicate a good positive relationship with the clay mineral content and a negative relationship with the organic matter content, indicating that the pores less than $1 \mathrm{~nm}$ are mainly intergranular pores, interlaminar pores, and intermolecular pores of clay minerals. A correlation between the 1$2 \mathrm{~nm}$ pores and the organic matter and clay mineral contents was also observed, however, it was not obvious and pores may have been influenced by both minerals. The volume ratio of pores between 1 and $2 \mathrm{~nm}$ was mainly influenced by the clay minerals, while the organic matter skeleton pores also contributed to the pore volume. These conclusions are consistent with the lens-observation results.

4.2. Classification of Micropore Types. Currently, the pores of shale reservoirs are classified as micropores, mesopores, and macropores according to their pore size or organic and inorganic pores according to their origin. These classification schemes are based on the results of SEM observation, and the genetic types of micropore have not been classified. This paper-based observation on TEM, according to the origin, size and distribution propose a scheme for the classification of micropores (Table 3 ).

4.3. Geological Significance of Micropores. Under the same pore volume conditions, micropores have a larger specific surface area and can store more gas. Javadpour proposed that in addition to adsorbed and free gas, some gas in shale reservoirs exists as dissolved gas in organic matter [17]. This
TABLE 4: Gas production of typical wells in the Fuling shale gas field.

\begin{tabular}{lcccc}
\hline Well & $\begin{array}{c}\text { Reserves- } \\
\text { static method } \\
\left(10^{8} \mathrm{~m}^{3}\right)\end{array}$ & $\begin{array}{c}\text { Cumulative gas } \\
\text { production } \\
\left(10^{8} \mathrm{~m}^{3}\right)\end{array}$ & $\begin{array}{c}\text { Production } \\
\text { time (a) }\end{array}$ & $\begin{array}{c}\text { Current } \\
\text { daily output } \\
\left(10^{4} \mathrm{~m}^{3}\right)\end{array}$ \\
\hline A & 3.81 & 3.2 & 5.5 & 4.9 \\
B & 2.86 & 2.4 & 5.5 & 8.8 \\
C & 2.1 & 1.4 & 3.1 & 6.6 \\
D & 1.5 & 1.2 & 2 & 6.2 \\
E & 1.6 & 0.9 & 2 & 4.5 \\
\hline
\end{tabular}

portion of gas has not been the focus of research. Under the current production situation of the Fuling shale gas field, the calculation of the adsorbed and free gas reserves is inconsistent with the actual production situation. In the five wells listed in Table 4, the cumulative gas production was close to the calculated reserves; however, the current daily production was relatively high, demonstrating that the reserves have been significantly underestimated. Therefore, the micropores may have a higher gas storage capacity than initially estimated. Some scholars have also reported that if the pore surface is wet, the pore diameter exceeds $5 \mathrm{~nm}$, allowing the entry of methane molecules. Organic matter is not wet. Although clay minerals are wet, the original state of the water molecules in the formation is not yet understood, and the presence of water preventing gas storage in micropores has not yet been confirmed. Therefore, strengthening the pore gas storage mechanism and storage capacity calculation methods is of great significance for calculating shale gas reserves.

Gas movement in shale reservoirs can be divided into five layers [15]. The smallest scale is the molecular scale. At this scale, methane molecules move from the inside of the organic matter and clay to the nanoscale pores. Through TEM observations, it can be found that the mineral particles and organic matter skeletons that constituted the shale contained spaces. The intercrystalline pore diameter of brittle minerals, such as quartz, was smaller than that of methane molecules. The clay mineral particles within the smaller intergranular pores, interlaminar pores, and intermolecular pores are available for the storage and transport of gas molecules, causing the movement of gas in different spaces.

Organic matter skeleton pores creating interconnections between mesoporous and macroporous are providing channels for molecular diffusion of gas. In the accumulation and development phases, methane molecules can reach all of the nano- and microlevels of the shale reservoir pores and fractures. Therefore, all of the gas molecules can flow between the pores, there are no invalid pores, and all of the gas can be used.

\section{Conclusions}

(1) Field emission SEM and TEM can be used to observe pores larger than $0.2 \mathrm{~nm}$ in the shale reservoir. The NMR method can better characterize the distribution of micropores than the adsorption-mercury injection method 
(2) A large number of micropores are distributed between the mesopores and macropores of the shale reservoir, including inorganic micropores and organic micropores. Inorganic micropores mainly including the intergranular pores, interlaminar pores, intermolecular pores of clay minerals, and intercrystalline pores of brittle mineral. Organic micropores are mainly organic matter skeleton pores

(3) The volume ratio of micropores directly proportional to the content of clay minerals and inversely proportional to the content of organic matter. The development of pores smaller than $1 \mathrm{~nm}$ was mainly controlled by the clay mineral content, and the development of pores with a size of approximately 1-2 nm was related to the contents of clay minerals and organic matter

(4) Micropores can well connect mesopores and macropores in the reservoir, which is of great significance in the gas molecule storage and flow processes; however, its occurrence mechanism and flow efficiency need to be further studied

\section{Data Availability}

The [DATA TYPE] data used to support the findings of this study are included within the article.

\section{Conflicts of Interest}

The authors declare that they have no conflicts of interest.

\section{Acknowledgments}

This work was supported by the Science and Technology Innovation foundation of CNPC under Grant 2020D5007-0209, Enshi Science and Technology Project under Grant XYJ2020000050, and National Science and Technology Major Project during 13th Five-Year under Grants 2016ZX05060-009 and 2016ZX05060-019.

\section{References}

[1] C. Zou, D. Dong, S. Wang et al., "Geological characteristics, formation mechanism and resource potential of shale gas in China," Petroleum Exploration and Development, vol. 67, no. 6, pp. 641-653, 2010.

[2] P. Singh, R. Slatt, G. Borges et al., "Reservoir characterization of uncon-ventional gas shale reservoirs: example from the Barnett Shale, Texas, USA," Oklahoma City Geological Society, vol. 60, no. 1, pp. 15-31, 2009.

[3] IUPAC (International Union of Pure and Applied Chemistry), Physical Chemistry Division Commission on Colloid and Surface Chemistry, "Subcommittee on characterization of porous solids: recommendations for the characterization of porous solids (technical report)," Pure and Applied Chemistry, vol. 66, no. 8, pp. 1739-1758, 1994.

[4] G. Chalmers and R. M. Bustin, A pore by any other name wouldbe as small: the importance of meso-and microporosity in shale gascapacity, AAPG Annual Convention and Exhibition, Denver, 2009.

[5] R. G. Loucks, R. M. Reed, S. C. Ruppel, and D. M. Jarvie, "Morphology, genesis, and distribution of nanometer-scale pores in siliceous mudstones of the Mississippian Barnett Shale," Journal of Sedimentary Research, vol. 79, no. 12, pp. 848-861, 2009.

[6] R. J. Ambrose, R. C. Hartman, M. Diaz-Campos, I. Y. Akkutlu, and C. H. Sondergeld, "New pore-scale considerations for shale gas in place calculations," in Paper presented at the SPE Unconventional Gas Conference, Pittsburgh, Pennsylvania, USA, 2010SPE 131772.

[7] R. G. Loucks and S. C. Ruppel, "Mississippian Barnett Shale: lithofacies and depositional setting of a deep-water shale-gas succession in the Fort Worth Basin, Texas," AAPC Bulletin, vol. 91, no. 4, pp. 579-601, 2007.

[8] F. J. Cale, R. M. Reed, and J. Holder, "Natural fractures in the Barnett Shale and their importance for hydraulic fracture treatments," AAPG Bulletin, vol. 91, no. 4, pp. 603-622, 2007.

[9] C. Yiming, W. Xiuli, and H. Xu, "Suggestions from the research of pore types of shale gas reservoir in North America," Complex Hydrocarbon Reservoirs, vol. 5, no. 4, pp. 1922, 2012.

[10] R. M. Slatt and N. R. O'Brien, "Pore types in the Barnett and Woodford gas shales: contribution to understanding gas storage and migration pathways in fine-grained rocks," AAPG Bulletin, vol. 95, no. 12, pp. 2017-2030, 2011.

[11] D. Beliveau, "Honey, I shrunk the pores!," Journal of Canadian Petroleum Technology, vol. 32, no. 8, pp. 15-17, 1993.

[12] G. R. L. Chalmers and R. Marc Bustin, "On the effects of petrographic composition on coalbed methane sorption," International Journal of Coal Geology, vol. 69, no. 4, pp. 288-304, 2007.

[13] G. R. L. Chalmers and R. M. Bustin, "Lower Cretaceous gas shales in northeastern British Columbia: part I. geological controls on methane sorption capacity," Bulletin of Canadian Petroleum Geology, vol. 56, no. 1, pp. 1-21, 2008.

[14] D. J. K. Ross and R. Marc Bustin, "The importance of shale composition and pore structure upon gas storage potential of shale gas reservoirs," Marine and Petroleum Geology, vol. 26, no. 6, pp. 916-927, 2009.

[15] F. Javadpour, "Nanoscale gas flow in shale gas sediments," The Journal of Canadian Petroleum Technology, vol. 46, no. 10, pp. 55-61, 2007.

[16] P. Marschall, S. Horseman, and T. Gimmi, "Characterisation of gas transport properties of the Opalinus Clay, a potential host rock formation for radioactive waste disposal," Oil \& Gas Science and Technology, vol. 60, no. 1, pp. 121-139, 2005.

[17] F. Javadpour, "Nanopores and apparent permeability of gas flow in mudrocks (shales and siltstone)," Journal of Canadian Petroleum Technology, vol. 48, no. 8, pp. 16-21, 2009.

[18] R. Gareth and R. Chalmers, "Characterization of gas shale pore systems by porosimetry, pycnometry, surface area, and field emission scanning electron microscopy/transmission electron microscopy image analyses: examples from the Barnett, Woodford, Haynesville, Marcellus, and Doig units," AAPG Bulletin, vol. 96, no. 6, pp. 1099-1119, 2012.

[19] C. H. Sondergeld, R. J. Amhrose, C. C. Rai, and J. Moncrieff, "Micro-structural studies of gas shales," in Paper presented at the SPE Unconventional Gas Conference, pp. 1-17, Pittsburgh, Pennsylvania, USA, 2010, SPE 131771. 
[20] C. R. Clarkson, N. Solano, R. M. Bustin et al., "Pore structure characterization of North American shale gas reservoirs using USANS/SANS, gas adsorption, and mercury intrusion," Fuel, vol. 103, pp. 606-616, 2013.

[21] X. Guo, Y. Li, R. Liu, and Q. Wang, "Characteristics and controlling factors of micro-pore structures of Long maxi shale play in the Jiaoshiba area Sichuan Basin," Natural Gas Industry, vol. 34, no. 6, pp. 9-16, 2014. 